\section{Ameliorative effect of gallic acid on methotrexate-induced hepatotoxicity and nephrotoxicity in rat}

\section{Ebenezer Tunde Olayinka, Ayokanmi Ore, Oluwatobi Adewumi Adeyemo, Olaniyi Solomon Ola}

Biochemistry Unit, Department of Chemical Sciences, Ajayi Crowther University, Oyo, Oyo State, Nigeria

\section{Abstract}

We investigated the protective effect of gallic acid (GA) against methotrexate (MTX)-induced hepatotoxicity and nephrotoxicity. Male Wistar rats were randomized into five groups ( $n=$ 6/group): I, control; II, MTX-treated for seven days; III, pre-treated with GA for seven days, followed by MTX for seven days; IV, co-treated with MTX and GA for seven days and V, GA for seven days. MTX caused a significant increase $(\mathrm{P}<0.05)$ in plasma biomarkers of nephrotoxicity (urea, creatinine) and hepatotoxicity (Bilirubin, alkaline phosphatase, aspartate aminotransferase, alanine aminotransferase, gamma glutamyl transferase) when compared with control. Furthermore, MTX caused a significant decrease in the activities of hepatic enzymic antioxidants (superoxide dismutase, catalase, glutathione S-transferase) and nonenzymic antioxidants (Vitamin $\mathrm{C}$ and glutathione), followed by a significant increase in hepatic malondialdehyde content. However, pretreatment and co-treatment with gallic acid ameliorated the MTX-induced biochemical changes observed. Taken together, GA protected against MTX-induced hepatotoxicity and nephrotoxicity in rats, by reducing the impact of oxidative damage to tissues.

\section{Introduction}

Methotrexate (MTX), (Figure 1A) is an antimetabolite and a 4-amino, 10-methyl analogue of folate that inhibit dihydrofolate reductase (DHFR), involved in the formation of tetrahydrofolate from dihydrofolate and consequently inhibiting DNA synthesis and cell proliferation. ${ }^{1}$ MTX is a cytotoxic agent used in the treatment of leukaemia and various malignancies, as well as in non-neoplastic diseases such as psoriasis, rheumatoid arthritis and as anti-inflammatory and immunosuppressive agent. $^{1-3}$ Earlier studies have revealed that MTX is converted mainly to metabolites connected to glutamate (MTX-glu) in cells and tis- sues. ${ }^{4}$ The complex so formed is referred to as polyglutamated forms which is responsible for most biochemical activities of MTX. ${ }^{5}$

MTX is known to generate reactive oxygen species (ROS) in both normal and cancer cells resulting in oxidative damage. ${ }^{6}$ The anticancer, anti-inflammatory and immunosuppressive actions of MTX has been shown to occur via ROS generation and induction of apoptosis. ${ }^{7}$ MTX has been reported to induce renal and hepatic toxicity via oxidative stress and its efficacy has been limited by severe organ toxicity. ${ }^{8,9}$

In the regulation of oxidative processes, cellular systems have been equipped with several antioxidant defense mechanisms, and there are several phytochemicals of plant origin with inherent antioxidant properties that are capable of boosting cellular enzymic and nonenzymic antioxidant indices thus making them excellent scavengers of free radicals. ${ }^{10}$ The chemoprotective properties of plant extracts have been extensively studied and are attributed to the presence of flavonoids, anthocyanins and phenolic compounds. ${ }^{11}$ Gallic acid (GA) (3,4,5-trihydroxybenzoic acid) (Figure 1B) is a naturally occurring phenolic compound present in green tea, gall nut, grapes, red wine, hops, oak bark etc. ${ }^{12}$ Several authors have reported that GA possess strong antioxidant properties and a wide array of biological and pharmacological activities such as free radical scavenging, anti-apoptotic and anti-inflammatory. ${ }^{13}$ Other reported biological effects include protection against doxorubicin-induced myocardial toxicity and cyclophosphamideinduced oxidative stress. ${ }^{14}$

The present study is therefore aimed at evaluating the protective effect of gallic acid pre-treatment and co-treatment on methotrexate-induced hepatotoxicity, nephrotoxicity and oxidative stress in rats. In this study, the role of GA in MTX induced hepatotoxicity and renal toxicity was evaluated by assessing plasma biomarkers of hepatic and renal function as well as selected oxidative stress markers (level of lipid peroxidation, enzymic and non enzymic antioxidants).

\section{Materials and Methods}

\section{Drug, chemicals and reagents}

Methotrexate tablets is a product of West Coast Pharmaceutical Works Ltd, Gota, Ahmedabad, India; Gallic acid, Glutathione, 1chloro-2,4-dinitrobenzene (CDNB),5,5 -dithio bis-2-nitrobenzoic acid (DTNB), epinephrine, and hydrogen peroxide $\left(\mathrm{H}_{2} \mathrm{O}_{2}\right)$, were obtained from Sigma ${ }^{\circledR}$ Chemical Company, London, UK; Assay kits for alanine aminotransferase (ALT), aspartate aminotransferase (AST), gamma glutamyl transferase (GGT), alkaline phos-
Correspondence: Ayokanmi Ore, Department of Chemical Sciences, Ajayi Crowther University, PMB 1066, Oyo, Oyo State, Nigeria.

Tel.: +2348061656814.

E-mail: oreayokanmi@gmail.com

Key words: Methotrexate; hepatotoxicity; nephrotoxicity; gallic acid; rat

Contributions: ETO designed the study; A0, OAA and OSA were involved in the animal treatments, laboratory and statistical analysis. OAA prepared the manuscript. AO handled all correspondence regarding the manuscript. The final version was read and approved by all authors.

Conflict of interest: the authors declare no potential conflict of interest.

Received for publication: 14 June 2016.

Revision received: 13 August 2016.

Accepted for publication: 15 August 2016.

This work is licensed under a Creative Commons Attribution NonCommercial 4.0 License (CC BYNC 4.0).

(C) Copyright E.T. Olayinka et al., 2016

Licensee PAGEPress, Italy

Journal of Xenobiotics 2016; 6:6092

doi:10.4081/xeno.2016.6092

phatase (ALP), urea, Creatinine, total bilirubin were purchased from Randox ${ }^{\circledR}$ Laboratories Ltd. (Antrim, UK). All other reagents used were of analytical grade and of highest purity.

\section{Animals}

Male rats (Wistar strain) weighing between 160-180 g were obtained from the animal housing unit, in the Department of Chemical Sciences, Ajayi Crowther University, Oyo, Nigeria. The rats were acclimatized under laboratory conditions prior to experiment. The animals were housed in wire-meshed cages and provided with water and food ad libitum. They were fed with commercial rat diet (Ladokun ${ }^{\circledR}$ Feeds, Nigeria Ltd Ibadan, Nigeria). The study was approved by the ethical committee of the Faculty of Natural Sciences, Ajayi Crowther University, Oyo, Nigeria. Handling of the experimental animals was done in accordance with international guidelines on the care and use of experimental animals (National Research Council). ${ }^{15}$

\section{Experimental design}

Thirty rats were randomly assigned into five experimental groups (I-V) of six animals each. The animals of each group were treated as presented in Table 1 . The dose for MTX $(0.2$ $\mathrm{mg} / \mathrm{kg} \mathrm{bw}$ ) was selected based on the recommended adult dose for rheumatoid arthritis and other inflammatory diseases while the dose for GA ( $20 \mathrm{mg} / \mathrm{kg}$ bw) was arrived at based 
on available literature. ${ }^{16}$ The respective doses were prepared based on the average weight of animals in each treatment groups and administered in one $\mathrm{mL}$ of distilled water. The drug doses were administered once daily by oral intubation.

\section{Plasma and tissue preparation}

Blood samples were collected from each animal, via retro orbitals plexus in heparinized sample tubes (Li heparin). Animals were sacrificed and liver was collected from each animal for preparation of the post-mitochondrial fraction (PMF).

Centrifugation of blood samples were done at $4000 \mathrm{rpm}$ for 5 minutes in a bench centrifuge (Analytica, Athens, Greece). The plasma obtained were stored at $-4^{\circ} \mathrm{C}$ for subsequent plasma assays. Liver samples were rinsed in ice-cold $1.15 \% \mathrm{KCl}$ and homogenized in 4 volumes of $0.01 \mathrm{M}$ potassium phosphate buffer ( $\mathrm{pH}$ 7.4). The homogenates obtained were subjected to centrifugation at $12,500 \times g$ for $15 \mathrm{~min}$ at $-4^{\circ} \mathrm{C}$ in a refrigerated centrifuge (Eppendorf UK Ltd., Stevenage, UK) and supernatants (PMF) were collected in sample tubes and used for subsequent biochemical assays.

\section{Biochemical analysis}

\section{Total protein}

The protein concentration in the liver PMF was determined according to the biuret method of Gornall et al. ${ }^{17}$

\section{Biomarkers of renal function}

Plasma level of creatinine and urea were determined with RANDOX ${ }^{\circledR}$ diagnostic kits following the manufacturer's protocol. The method for creatinine assays was based on Jaffe $^{18}$ and the method of Tietz ${ }^{19}$ was employed for plasma urea determination.

\section{Biomarkers of hepatic function}

Plasma total bilirubin (TBILI) level, and activities of alkaline phosphatase (ALP), alanine aminotransferase (ALT), aspartate aminotransferase (AST), and gamma glutamyl transferase $(\gamma$-GT) were assayed using RANDOX ${ }^{\circledR}$ diagnostic kits based on the manufacturer's procedure. Assay of TBILI level was based on the method of Tietz et al..$^{20}$ Activity of ALP was determined according to Tietz et al. ${ }^{20}$ Plasma activities of ALT and AST were measured according to the method of Reltman and Frankel. ${ }^{21}$ The plasma activity of $\gamma$-GT was determined following the method described by Szasz.22

\section{Biomarkers of oxidative stress}

The level of hepatic reduced glutathione (GSH) was determined following the method of Jollow et al. ${ }^{23}$ Ellman's reagent reacts with reduced glutathione, and the chromophoric product resulting from the reaction has a molar absorption at $412 \mathrm{~nm}$. The level of vitamin $\mathrm{c}$ in the liver PMF was determined according to Jagota and Dani. ${ }^{24}$ Vitamin $\mathrm{C}$ in samples reacts with Folin-phenol reagent resulting in blue chromophore which has maximum absorption at $760 \mathrm{~nm}$. Hepatic GST activity was measured following the method of Habig et $a l .{ }^{25}$ The procedure described by Misra and Fridovich ${ }^{26}$ was used for the determination of hepatic superoxide dismutase activity. Hepatic catalase activity was determined by the method described by Singha. ${ }^{27}$ Hepatic level of lipid peroxidation (LPO) was determined by the method described by Vashney and Kale. ${ }^{28}$ This assay involved the reaction between thiobarbituric acid and malondialdehyde (MDA) a product of lipid peroxidation to yield a stable pink chromophore which absorbs maximally at $532 \mathrm{~nm}$.

\section{Statistical analysis}

Data are presented as the mean \pm standard deviation (SD) of six replicates. Statistical significance was determined by one-way analysis of variance (ANOVA) followed by Duncan's multiple comparison between control and treated rats in all groups using Sigma plot ${ }^{\circledR}$ statistical package (Systat Software Inc., San Jose, CA, USA). P-values less than $0.05(\mathrm{P}<0.05)$ were considered statistically significant.

\section{Results}

\section{Protective effects of gallic acid on} MTX-induced changes in markers of hepatic and renal toxicity

As presented in Table 2, administration of MTX caused a significant $(\mathrm{P}<0.05)$ increase in plasma creatinine and urea levels (124\% and $68.5 \%$ respectively) compared to control. However, pre-treatment and co-treatment of GA with MTX attenuated the observed elevated plasma urea and creatinine levels when compared with the MTX-treated group.

The plasma level of total bilirubin (TBILI) and alkaline phosphatase (ALP) activity (biomarkers of hepatobiliary damage) increased

Table 1. Experimental design.

\begin{tabular}{lcc} 
Treatment-Groups & \multicolumn{2}{c}{ Treatments-Duration } \\
& Day 1-7 & Day 8-14 \\
I (CTRL) & - & Control; distilled water \\
II (MTX) & - & $0.2 \mathrm{mg} / \mathrm{kg}$ bw MTX \\
\hline III (MTX + GA) (pre-treated) & $20 \mathrm{mg} / \mathrm{kg} \mathrm{bw} \mathrm{GA}$ & $0.2 \mathrm{mg} / \mathrm{kg}$ bw MTX \\
IV (MTX + GA) (co-treated) & - & $0.2 \mathrm{mg} / \mathrm{kg} \mathrm{bw} \mathrm{MTX} \mathrm{+} 20 \mathrm{mg} / \mathrm{kg} \mathrm{bw} \mathrm{GA}$ \\
\hline V GA & - & $20 \mathrm{mg} / \mathrm{kg}$ bw GA \\
\hline
\end{tabular}

CTRL, control; MTX, methotrexate; GA, gallic acid.

Table 2. Ameliorative effect of gallic acid pre-treatment and co-treatment on methotrexate-induced changes in plasma biomarkers of renal and hepatic function in rat.

\begin{tabular}{|c|c|c|c|c|c|}
\hline Group Parameter & Control & MTX & $\begin{array}{c}\text { MTX + GA } \\
\text { (pre-treated) }\end{array}$ & $\begin{array}{c}\text { MIX + GA } \\
\text { (co-treated) }\end{array}$ & GA \\
\hline Creatinine (mg/dL) & $0.98 \pm 0.13$ & $2.2 \pm 0.1^{*}$ & $1.4 \pm 0.1^{\mathrm{a}}$ & $1.5 \pm 0.1^{\mathrm{a}}$ & $1.2 \pm 0.1$ \\
\hline Urea (mg/dL) & $35.0 \pm 1.2$ & $59.0 \pm 2.6^{*}$ & $43.2 \pm 2.3^{\mathrm{a}}$ & $45.5 \pm 3.2^{\mathrm{a}}$ & $39.4 \pm 2.9$ \\
\hline TBILI (mg/dL) & $0.36 \pm 0.02$ & $0.86 \pm 0.03^{*}$ & $0.47 \pm 0.02^{\mathrm{a}}$ & $0.49 \pm 0.02^{\mathrm{a}}$ & $0.43 \pm 0.02$ \\
\hline $\operatorname{ALP}(\mathrm{U} / \mathrm{L})$ & $157.4 \pm 6.4$ & $406.8 \pm 7.3^{*}$ & $268.8 \pm 1.9^{a}$ & $327.4 \pm 1.4^{a}$ & $287.0 \pm 7.5$ \\
\hline $\operatorname{ALT}(\mathrm{U} / \mathrm{L})$ & $21.5 \pm 1.6$ & $43.6 \pm 2.4^{*}$ & $26.9 \pm 1.6^{\mathrm{a}}$ & $33.0 \pm 2.2^{\mathrm{a}}$ & $26.8 \pm 2.4$ \\
\hline AST (U/L) & $147.2 \pm 5.3$ & $284.1 \pm 6.3^{*}$ & $195.3 \pm 4.8^{\mathrm{a}}$ & $240 \pm 5.7^{\mathrm{a}}$ & $193.4 \pm 3.8$ \\
\hline GGT (U/L) & $1.5 \pm 0.2$ & $3.9 \pm 0.2^{*}$ & $2.1 \pm 0.1 \mathrm{a}$ & $2.3 \pm 0.1^{\mathrm{a}}$ & $1.7 \pm 0.2$ \\
\hline
\end{tabular}

Data are expressed as mean \pm S.D for six rats in each group. ${ }^{*}$ Significantly different from the control $(\mathrm{P}<0.05)$; ${ }^{\text {a }}$ ignificantly different from the methotrexate group $(\mathrm{P}<0.05)$; values in parenthesis represent percentage (\%) increase. 
significantly $(\mathrm{P}<0.05)$ in rats by $138.8 \%$ and $158 \%$ respectively following MTX treatment (Table 2). However, the levels of TBILI and ALP activity were significantly ameliorated in the plasma of animals pre-treated or co-treated with GA when compared with the MTX group.

MTX treatment also caused a significant increase in the activities of alanine aminotransferase (ALT), aspartate aminotransferase (AST), and gamma glutamyl transferase ( $\gamma$ GT) (biomarkers of hepatocellular toxicity) in the plasma of rats by $102.8 \%, 93 \%$ and $106.7 \%$ respectively compared to values in control (Table 2). Pre-treatment and co-treatment of GA with MTX significantly ameliorated the elevated activities of plasma ALT, AST, and $\gamma$-GT when compared to MTX-treated group.

Protective effects of gallic acid on MTXinduced changes in markers of oxidative stress. Hepatic SOD and catalase activity (Table 3) were significantly reduced in the MTX-treated group by $34.0 \%$ and $47.8 \%$ when compared with control $(\mathrm{P}<0.05)$. Also, hepatic GST activity (Figure 2) was also significantly reduced by $38.3 \%$ in the MTX-treated rats when compared with the control. However, GA pre-treatment and co-treatment significantly ameliorated the MTX-induced decrease in hepatic activities of SOD, CAT, and GST relative to the MTX-treated group $(\mathrm{P}<0.05)$.

Furthermore, hepatic ascorbic acid (AA) and GSH level (Figures 3 and 4) were significantly $(\mathrm{P}<0.05)$ decreased following treatment with MTX by $37.9 \%$ and $38.9 \%$ when compared with the control. Conversely, pre-treatment and cotreatment with GA significantly $(\mathrm{P}<0.05)$ protected against the MTX-induced decrease in hepatic AA and GSH levels when compared with the MTX group. In addition, the hepatic MDA level rose significantly $(\mathrm{P}<0.05)$ in the MTX-treated rats by $58.8 \%$ when compared with the control (Figure 5). However, GA pretreatment and co-treatment attenuated the increase in hepatic MDA relative to the MTX-<smiles>CN(Cc1cnc2nc(N)nc(N)c2n1)c1ccc(C(=O)N[C@@H](CCC(=O)O)C(=O)O)cc1</smiles><smiles>O=C(O)c1cc(O)c(O)c(O)c1</smiles>

Figure 1. Chemical structure of methotrexate (A) and gallic acid (B).

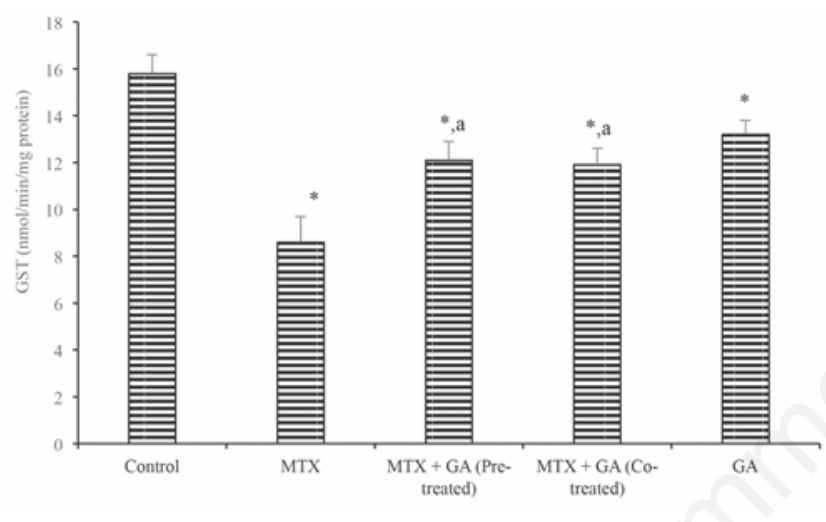

Figure 2. Ameliorative effect of gallic acid pre-treatment and cotreatment on methotrexate-induced reduction in hepatic glutathione S-transferase (GST) activity in rats. Data are expressed as mean \pm S.D for six rats in each group. ${ }^{*}$ Significantly different from the control $(P<0.05)$; ${ }^{\text {a }}$ significantly different from the methotrexate group $(\mathbf{P}<0.05)$.

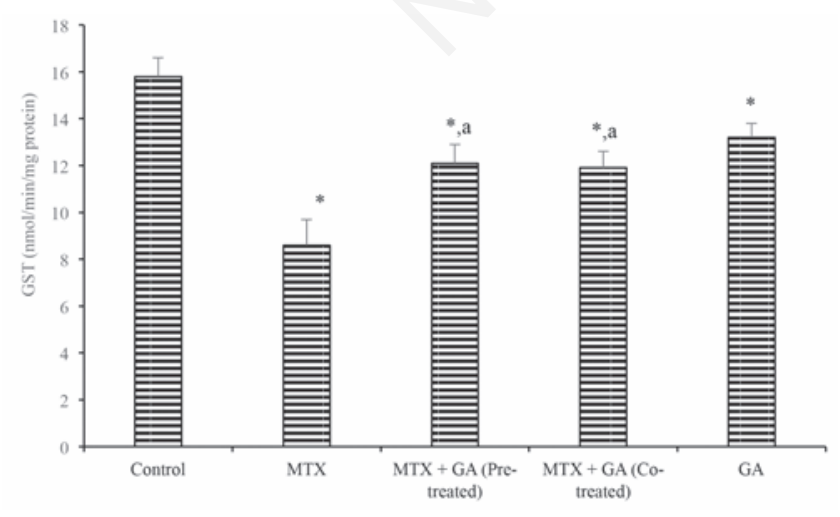

Figure 3. Ameliorative effect of gallic acid pre-treatment and cotreatment on methotrexate-induced reduction in hepatic vitamin $C$ level in rats. Data are expressed as mean \pm S.D for six rats in each group. ${ }^{*}$ Significantly different from the control $(P<0.05)$; ${ }^{a}$ significantly different from the methotrexate group $(P<0.05)$.

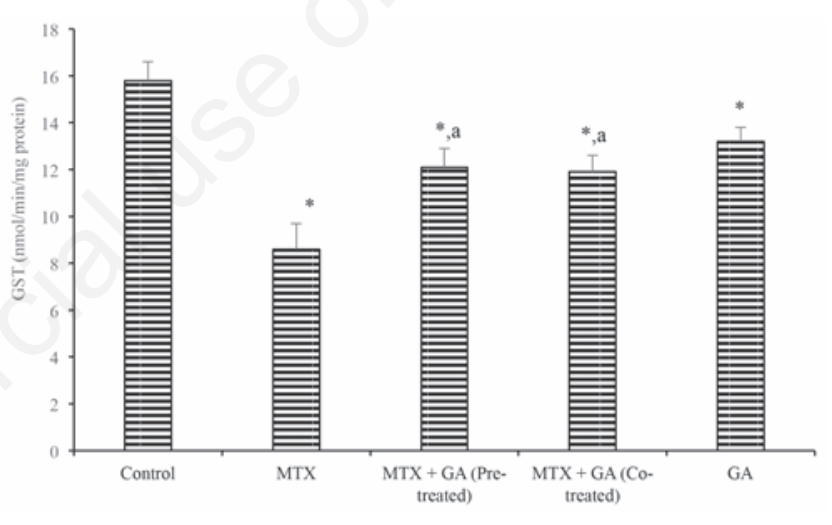

Figure 4. Ameliorative effect of gallic acid pre-treatment and cotreatment on methotrexate-induced reduction in hepatic glutathione (GSH) level in rats. Data are expressed as mean \pm S.D for six rats in each group. ${ }^{*}$ Significantly different from the control $(\mathrm{P}<0.05)$; asignificantly different from the methotrexate group $(\mathrm{P}<0.05)$.

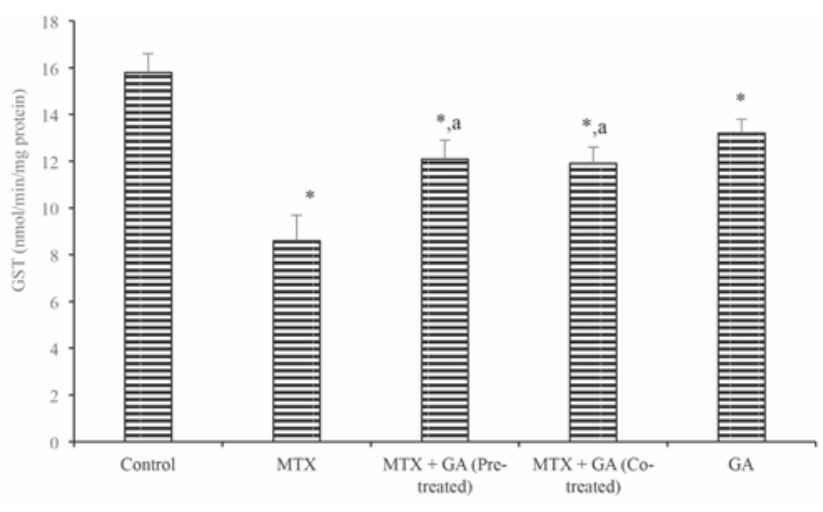

Figure 5. Ameliorative effect of gallic acid pre-treatment and co-treatment on methotrexate-induced increase in hepatic level of lipid peroxidation (MDA) in rats. Data are expressed as mean \pm S.D for six rats in each group. ${ }^{*}$ Significantly different from the control $(\mathbf{P}<0.05)$; ${ }^{\mathrm{a}}$ significantly different from the methotrexate group $(\mathrm{P}<0.05)$. 
treated group.

\section{Discussion and Conclusions}

Methotrexate (MTX) is a chemotherapeutic agent indicated in conditions such as autoimmune diseases, inflammatory myopathies, leukemia etc. However it is known to be associated with side effects including hepatotoxicity and nephrotoxicity; often mediated by reactive oxygen species (ROS). ${ }^{29-31}$ Recent studies have demonstrated the protective roles of phytochemicals in drug-induced organ toxicity. Gallic acid employed in the present study is a potent natural antioxidant with numerous biological activities including hepatoprotective activity. ${ }^{32-34}$

Biomarkers of renal function: urea and creatinine were considered in this study. Urea and creatinine are metabolic products removed by the kidney from circulation. Increase in their plasma level is an indication of loss in renal function. ${ }^{35}$ The increase in plasma urea and creatinine observed in this study is in agreement with previous report on MTX. ${ }^{31}$ The attenuation of the level of plasma urea and creatinine by GA is an indication of improved renal function and the nephroprotective role of GA. ${ }^{36}$

The liver is the target of several xenobiotics including chemotherapeutic agents such as MTX. MTX is stored in the liver cells as MTXpolyglumates and has been linked to MTXinduced hepatotoxicity. ${ }^{37}$ The plasma level of bilirubin and activities of AST, ALT, ALP and GT are reliable indices of hepatotoxicity. ${ }^{38}$ Elevation of the plasma activities of AST and ALT have been linked to structural damage to the liver.$^{39}$ Bilirubin is present in the liver, bile, intestine and the reticuloendothelial cells of the spleen. High plasma bilirubin, ALP and GT levels are indicators of hepatobiliary injury. ${ }^{38,39}$ However, pre-treatment and cotreatment with GA ameliorated the MTXinduced cellular damages which agrees with previous finding on the hepatoprotective activity of GA. ${ }^{37}$

Oxidative stress has been identified as a toxicological mechanism of most chemotherapeutic drugs. Free radicals release and ROS plays a significant role in the MTX-induced hepatotoxicity and nephrotoxicity. ${ }^{30,31}$ In this study, MTX caused a significant decrease in the hepatic SOD, CAT, GST, GSH and vitamin C. SOD catalyses the rapid dismutation of superoxide anions to hydrogen peroxide $\left(\mathrm{H}_{2} \mathrm{O}_{2}\right)$ and molecular oxygen, while CAT converts the $\mathrm{H}_{2} \mathrm{O}_{2}$ formed to water and molecular oxygen. The low molecular weight antioxidants, vitamin $\mathrm{C}$ and GSH play an important role in cellular redox balance. They are the first line of defense against oxidation damages. ${ }^{40} \mathrm{AA}$ is involved in the preservation of tocopherol in membranes and lipoproteins, while GSH act as a substrate for several antioxidants enzymes such as glutathione peroxidase (GPx), glutathione $-\mathrm{S}$ - transferase (GST). ${ }^{41}$ GSTs are a family of proteins primarily involved in the detoxification of highly reactive electrophiles including drugs by it combined action with GSH as a conjugating agent. ${ }^{42}$ The reduction in the levels of the antioxidant defense system occasioned by MTX may predispose the liver to oxidative injury. However, GA significantly improved the antioxidant defense systems in the liver of rats in a similar manner to previous findings. ${ }^{43}$ Lipid peroxidation induced by MTX is an indication of the involvement of free radicals in MTX-mediated toxicity. The amelioration of hepatic LPO by GA in the study may be related to the free radical scavenging properties of gallic acid. ${ }^{43,44}$

In summary, current findings suggest that gallic acid has the potential to protect against Methotrexate-induced hepatotoxicity and nephrotoxicity. In addition, the mechanism of protection by gallic acid may involve free - radical scavenging. Therefore, gallic acid may be employed as a co-therapy in MTX chemotherapy as a protection against chemotherapy-associated oxidative damage to tissues.

\section{Research highlights}

- Chemotherapy-associated oxidative stress is a relevant side effect of most anticancer agents.

Methotrexate (MTX) acts as an antimetabolite as its anticancer mechanism.

Gallic acid is a plant derived antioxidant.

Hepatotoxicity, nephrotoxicity and oxidative stress was observed following exposure to methotrexate.

Administration of gallic acid as a pre-treatment or co-administered with MTX ameliorated MTX induced toxicity in rats.

\section{References}

1. Sirotnak FM, Donsbach RC. The intracellular concentration dependence of antifolate inhibition of DNA synthesis in L1210 leukemia cells. Cancer Res 1974;34:33240.

2. Bonadonna G, Brusamolino E, Valagussa P, Rossi A, Brugnatelli L, Brambilla C, et al. Combination chemotherapy as an adjuvant treatment in operable breast cancer. N Engl J Med 1976;294:405-10.

3. Phillips DC, Woollard KJ, Griffiths HR. The anti-infammatory actions of methotrexate are critically dependent upon the production of reactive oxygen species. Br $\mathrm{J}$ Pharmacol 2003;138:501-11.
4. Galivan J, Nimec Z, Balinska M. Regulation of methotrexate polyglutamate accumulation in vitro: effects of cellular folate content. Biochem Pharmacol 1983; 32:3344-7.

5. Koizumi S. Imparment of methotrexate (MTX)-polyglutamate formation of MTXresistant K562 cell lines. Jpn J Cancer Res 1988;79:1230-7.

6. Conklin KA. Chemotherapy-associated oxidative stress: impact on chemotherapeutic effectiveness. Integr Cancer Ther 2004;3:294-300.

7. Huang CC, Hsu PC, Hung YC, Liao YF, Liu CC, Hour CT, et al. Ornithine decarboxylase prevents methotrexate-induced apoptosis by reducing intracellular reactive oxygen species production. Apoptosis 2005;10:895-907.

8. Cetin A, Kaynar L, Kocyigit I, Hacioglu SK, Saraymen R, Ozturk A, Sari I, et al. Role of grape seed extract on methotrexate induced oxidative stress in rat liver. Am J Chin Med 2008;36:861-72.

9. Saigal S, Singh RK, Poddar, B. Acute methotrexate toxicity presenting as multiorgan failure and acute pneumonitis: a rare case report. Indian J Crit Care Med 2012;16:225-7.

10. Yea Z, Zhanga J, Townsendb DM, Tew KD. Oxidative stress, redox regulation and diseases of cellular differentiation. Biochim Biophys Acta 2015;1850:1607-21.

11. Zhang HY, Wang LF. Theoretical elucidation on structure-antioxidant activity relationships for indolinonic hydroxylamines. Bioorg Med Chem Lett 2002;12:229-33.

12. Singleton VL. Naturally occurring food toxicants: phenolic substances of plant origin common in foods. Adv Food Res 1981;27:149-242.

13. Abdelwahed A, Bouhlel I, Skandrani I, Valenti K, Kadri M, Guiraud P, et al. Study of antimutagenic and antioxidant activities of gallic acid and 1,2,3,4,6-pentagalloylglucose from Pistacia lentiscus. Confirmation by microarray expression profiling. Chem Biol Interact 2007;165:113.

14. Olayinka ET, Ore A, Ola OS, Adeyemo OA. Ameliorative effect of gallic acid on cyclophosphamide-induced oxidative injury and hepatic dysfunction in rats. Med Sci 2015;3:78-92.

15. National Research Council. Guide for the care and use of laboratory animals, 8th ed. Washington, DC: National Research; The National Academies Press; 2011.

16. Punithavathi VR, Prince PS, Kumar R, Selvakumari J. Antihyperglycaemic, antilipid peroxidative and antioxidant effects of gallic acid on streptozotocin induced diabetic Wistar rats. Eur J Pharmacol 2011;650:465-71. 
17. Gornall AC, Bardwawill CJ, David MM Determination of serum protein by means of the biuret reaction. J Biol Chem 1949;177:751-6.

18. Jaffe ER. Oxidative hemolysis, or what made the red cell break? N Engl J Med 1972;286:156-7.

19. Tietz NW. Clinical guide to laboratory tests, 3rd ed. Philadelphia, PA: W.B. Saunders Company; 1995.

20. Tietz NW, Pruden EL, Siggaard-Andersen 0. Liver function. In: Burtis AC, Ashwood ER, eds. Tietz textbook of clinical chemistry. London: WB Saunders; 1994. pp 1354-74.

21. Reltman S, Frankel SA. Colorimetric method for the determination of serum ALT and AST. Am J Clin Pathol 1957;28:5663.

22. Szasz G. A kinetic photometric method for serum Y-glutamyl transpeptidase. Clin Chem 1969;15:124-36.

23. Jollow DJ, Mitchell JR, Zampaghone N, Gillete JR. Bromobenzene induced liver necrosis, protective role of glutathione and evidence for 3,4-bromobenzene oxide as the hepatotoxic metabolite. Pharmacology 1974;11:151-69.

24. Jagota SK, Dani HM. A new colorimetric technique for the estimation of vitamin $\mathrm{C}$ using Folin phenol reagent. Anal Biochem 1982;127:178-82.

25. Habig WA, Pabst MJ, Jacoby WB. Glutathione transferases. The first enzymatic step in mercapturic acid formation. J Biol Chem 1974;249:7130-9.

26. Misra HP, Fridovich I. The role of superoxide anion in the autoxidation of epinephrine and a simple assay for superoxide dismutase. J Biol Chem 1972;247:3170-5.

27. Singha AK. Colorimetric assay of catalase. Anal Biochem 1972;47:389-94.

28. Varshney R, Kale RK. Effect of calmodulin antagonist on radiation induced lipid peroxidation in microsomes. Int J Radiat Biol 1990;58:733-43.

29. Tousson E, Zaki ZT, Abu-Shaeir WA, Hassan H. Methotrexate-induced hepatic and renal toxicity: role of L-carnitine in treatment. Biomed Biotechnol 2014;2:8592.

30. Johovic N, Cevik H, Sehirli OA, Yegen BÇ, Şener G. Melatonin prevents methotrexate induced hepatorenal oxidative injury in rats. J Pineal Res 2003;34:282-7.

31. Gressier B, Lebegue S, Brunet C, Luyckx M, Dine T, Cazin M, et al. Pro-oxidant properties of methotrexate: evaluation and prevention by an anti-oxidant drug. Pharmazie 1994;49:679-81.

32. Priscilla, DH, Prince PS. Cardioprotective effect of gallic acid on cardiac troponin-T, cardiac marker enzymes, lipid peroxidation products and antioxidants in experimentally induced myocardial infarction in Wistar rats. Chem Biol Interact 2009;179:118-24.

33. Kaur M, Velmurugan B, Rajamanickam S, Agarwal R, Agarwal C. Gallic acid, an active constituent of grape seed extract, exhibits anti-proliferative, pro-apoptotic and antitumorigenic effects against prostate carcinoma xenograft growth in nude mice. Pharm Res 2009;26:2133-40.

34. Rasool MK, Sabina EP, Ramya SR, Preety P, Patel S, Mandal N, et al. Hepatoprotective and antioxidant effects of gallic acid in paracetamol-induced liver damage in mice. J Pharm Pharmacol 2010;62:638-43.

35. George GS, Wakasi ME, Egoro E. Creatinine and urea levels as critical markers in end-stage renal failure. Res Rev J Med Health Sci 2014;3:41-4.

36. Uz E, Oktem F, Yilmaz HR, Uzar E, Ozgüner F. The activities of purine catabolizing enzymes and the level of nitric oxide in rat kidneys subjected to methotrexate: protective effect of caffeic acid phenethyl ester. Mol Cell Biochem 2005;277:165-70.

37. Vardi N, Parlakpinar H, Cetin A, Erdogan A, Ozturk C. Protective effect of $\beta$-carotene on methotrexate-induced oxidative liver damage. Toxicol Pathol 2010;38:592-7.

38. Boone L, Meyer D, Cusick P, Ennulat D, Bolliger AP, Everds N, et al. Selection and interpretation of clinical pathology indicators of hepatic injury in preclinical studies. Vet Clin Pathol 2005;34:182-8.

39. Ramaiah SK. A toxicologist guide to the diagnostic interpretation of hepatic biochemical parameters. Food Chem Toxicol 2007;45:1551-7.

40. Devasagayam TPA, Tilak JC, Boloor KK, Sane KS, Ghaskadbi SS, Lele RD. Free radicals and antioxidants in human health: current status and future prospects. JAPI 2004;52:794-804.

41. Kojo S. Vitamin C: basic metabolism and its function as an index of oxidative stress. Curr Med Chem 2004;11:1041-64.

42. Morgenstern R, Zhang J, Johansson K. Microsomal glutathione transferase: Mechanism and functional roles. Drug Metab Rev 2011;43:300-6.

43. Mahmoud RH, Barakat H. The protective effect of gallic acid and caffeine against cCl4-induced oxidative hepatotoxicity and mitochondrial DNA depletion in male albino rats. Egypt $\mathrm{J}$ Biochem Mol Biol 2010;28:543-62.

44. Masella R, di Benedetto R, Var R, Filesi C, Giovannini, C. Novel mechanisms of natural antioxidant compounds in biological systems: involvement of glutathione and glutathionerelated enzymes. J Nutr Biochem 2005;16:577-86. 